\title{
Up-Regulated Expression of miR-23a/b Targeted the Pro-Apoptotic Fas in Radiation-Induced thymic Lymphoma
}

\author{
Bailong Lia,c Mingjuan Sun ${ }^{b, c}$ Fu Gao a,c Wen Liu ${ }^{a}$ Yanyong Yang ${ }^{a}$ Hu Liu ${ }^{a}$ \\ Ying Cheng ${ }^{a}$ Cong Liu ${ }^{a}$ Jianming Cai ${ }^{a}$ \\ a Department of Radiation Medicine, Second Military Medical University, ${ }^{b}$ Department of Biochemistry \\ and Molecular Biology, Second Military Medical University, Shanghai, PR China; 'These authors \\ contributed equally to this work
}

\section{Key Words}

Radiation carcinogenesis $•$ Radiation induced thymic lymphoma $•$ miR-23 $•$ Fas

\begin{abstract}
Background: MicroRNAs (miRNAs) are small, single-stranded, noncoding RNAs, which usually bind to the 3'-untranslated region of target mRNAs and are capable of inducing posttranscriptional gene regulation by blocking translation or by degrading the target mRNA. However, the expression level of miR-23 in radiation induced carcinogenesis is largely unknown. Methods: Radiation induced thymic lymphoma model in BALB/c mice was set up. miR-23a \& miR-23b miRNA levels in different tissues and cells were detected by real-time qPCR. miR-23a/b inhibitor and miR-23a/b mimics were transfected to lymphoma cells and the target of miR-23a/b was identified by microRNA target prediction and Luciferase assays. Results: We found that miR-23a \& miR-23b were up-regulated in radiation induced thymic lymphoma tissue samples. Cell death and apoptosis were increased by miR-23a/b inhibitor and decreased by miR-23a/b mimics in lymphoma cells. Computational analysis found a putative target site of miR-23a/b in the 3'UTR of Fas mRNA, which was verified by luciferase reporter assay. Forced over-expression of miR-23a/b decreased the level of Fas protein. Moreover, over-expression of Fas rescued the pro-proliferation effect of miR-23, indicating Fas is a direct mediator of miR-23 functions. Furthermore, contrast to miR-23a/b which was up regulated, the Fas expression level was down-regulated and inversely correlated with miR23 in split radiation induced lymphoma tissue samples. Finally, our data also indicates that miR-23a could repress Fas much more potent than miR-23b and the additional region besides conserved seed pairing enables miR-23a's higher regulation. Conclusions: In this study, using a radiation induced thymic lymphoma model in BALB/c mice, We conclude that the expression of $\mathrm{miR}-23 \mathrm{a} / \mathrm{b}$ is up-regulated in radiation-induced thymic lymphoma and it maybe a novel therapeutic target of that cancer.
\end{abstract}




\section{Introduction}

MicroRNAs (miRNAs) are small, single-stranded, noncoding RNAs, which usually bind to the 3'-untranslated region of target mRNAs [1] and are capable of inducing posttranscriptional gene regulation by blocking translation or by degrading the target mRNA [1-6]. Studies have shown that miRNAs are involved in several human cancer, including lung cancer, liver cancer, chronic lymphocytic leukemia, gastric cancer, large cell lymphoma, and Burkitt's lymphoma [7-9]. Specifically, miR-23 has been shown to be enhanced in gcute lymphoblastic leukemia (ALL) [10], acute myeloid leukemia (AML) [10], gladder cancer [11], gastric cancer (stomach) [12], glioblastoma [13], pancreatic tumor [14], uterine leiomyoma [15], hepatocellular carcinoma [16] and other tumors [16, 17]. Even several important papers regarding miR-23 associated with cancer have reported, however, the expression level and the potential novel target of miR-23a and miR-23b in radiation induced carcinogenesis are largely unknown.

Radiotherapy is an important treat method for many types of cancers [18-20]. However, Ionizing radiation (IR) is a well-known carcinogen but the mechanism for radiation-induced carcinogenesis is still poorly understood $[21,22]$. Our previous studies have found that ERK1/2, STAT3, SHP-2 and TLR4 are also involved in $\gamma$-ray induced thymic lymphomas [2325]. However, the expression level of miR-23 in radiation induces thymic lymphomas is still not clear.

In this study, we described the up-regulated expression of miR-23a/b targeted the proapoptotic Fas in radiation-induced thymic lymphoma in BALB/c mice. To the best of our knowledge, this may be the first report of miR-23a/b in radiation induced thymic lymphoma in BALB/c mice.

\section{Materials and Methods}

\section{Mice and treatments}

Radiation-induced (4X $1.75 \mathrm{~Gy}$ ) thymic lymphoma model was as described in our previous work [2325]. A ${ }^{60} \mathrm{Co}$ irradiator was introduced for TBI irradiation [23-27]. In detail: un-anaesthetized mice were placed in well-ventilated plastic boxes and exposed to the ${ }^{60} \mathrm{Co}$ irradiator at a distance of $5 \mathrm{~m}$ from the source. Four weekly sub-lethal doses of 1.75 Gy gamma-ray irradiation was delivered at the dose rate of 0.58Gy/ $\mathrm{min}$. The mice were then released from the plastic box and allowed free access to food and drinking water.

RNA extraction and real-time PCR

RNA from different radiation induced thymic lymphoma tissues and normal thymus tissues was homogenized in RNASound ${ }^{\mathrm{TM}}$ RNA Extraction Card (Fortius Bio) and isolated according to the manufacturer's instructions. Reverse Transcription and Real-time PCR was subsequently performed in triplicate using the miScript RT Kit and miScript PCR system (Qiagen) specific for miR-23a and miR-23b as described detail in our previous studies [24, 28-30].

\section{Transfection}

Cells were cultured and transfected as described previously [24, 27, 28, 30]. Briefly, synthetic miR-s (mimics/inhibitors (anti-sense oligo, ASO), genepharm, shanghai, china) at a final concentration of 50nM were used for transfection. Transfection in NIH3T3 cells were using Lipofectamine 2000 (Invitrogen, ON, Canada) transfection reagent according to the manufacturer's instructions as described previously [24, 29]. Transfection in EL4 cell line (ATCC) was generated with Amaxa electroporation apparatus (Amaxa Biosystems, Koln, Germany) using manufacturer's protocols for each individual cell line (Amaxa Cell Line Nucleofector Kit L) as described previously with minor modifications [24, 31-33]. Cells were infected $48 \mathrm{~h}$ later and subjected to further experiments. 
Apoptosis assay

After different treatments, cells were labeled with annexin V-FITC and propidium iodide (PI) provided by BIPEC, following the manufacturer's instructions as described previously [6, 24, 26, 27, 29, 30, 34]. Samples were examined by Fluorescence Activated Cell Sorting (FACS) analysis, and the results were analyzed by using CellQuest software (Becton Dickinson, San Jose, CA) as described previously in our published paper $[24,27,30]$.

\section{Cell proliferation assay}

Cell proliferation assay were examined by MTT assay performed as described previously [24]. Briefly, after incubation for different time at $37^{\circ} \mathrm{C}$ in $5 \% \mathrm{CO}_{2}$, the unattached cells were removed by gentle washing with HANKS buffer. $100 \mathrm{uL}$ DMEM and $20 \mathrm{uL}$ MTT (5 mg/mL) (Sigma, USA) were added to each well. After incubation at $37^{\circ} \mathrm{C}$ for $4 \mathrm{~h}$, the medium was discarded. $200 \mathrm{uL}$ of $0.04 \mathrm{~mol} / \mathrm{L}$ hydrochloric acid in isopropanol was added to each well. The amount of MTT formazan product, which reflects the number of cells adhering to FN, was determined by measuring absorbance with a microplate reader at a test wavelength of $570 \mathrm{~nm}$ and a reference wavelength of $630 \mathrm{~nm}$.

\section{MicroRNA target prediction}

MiRNA targets were predicted using the algorithms TargetScan (http://www.targetscan.org), miRanda(http://www.cbio.mskcc.org/mirnaviewer), PicTar(http://www.pictar.bio.nyu.edu), miRGen and miRBase (http://www.microrna.sanger.ac.uk) [2-5].

\section{Plasmids}

The luciferase-3' UTR reporter constructs were generated by introducing the full length murine Fas 3'-UTR into pGL3 promoter vector (Promega) in a method similar to our published paper [24, 28-30]. We first amplified the wild type Fas 3'-UTR sequence by PCR using primers: Fas. F (5'-TGGAtctagaACTACCTCAGTTCCAGCCATGA-3') and Fas. R (5' -GCTGtctagaGAAATGCAAAAAGAGATACTTTAAT-3') and the murine genome cDNA were as a template. The PCR product was ligased into pGL3 promoter vector by the XbaI site. The mutated mouse Fas 3' UTR plasmid was directly synthesized by Jierui company (Jierui, shanghai, China). All PCR products were verified by DNA sequencing.

\section{Luciferase assay}

Luciferase assays were carried out in NIH3T3 cells (ATCC) as described previously [24, 28, 30]. Briefly, cells were first transfected with appropriate plasmids (TK renilla luciferase plasmids, wild type or mutated mouse Fas 3' UTR pGL3 promoter vector, synthetic miR-s (mimics/inhibitors (anti-sense oligo, ASO) with scramble control) in 24 -well plates. Then, the cells were harvested and lysised for luciferase assay $48 \mathrm{~h}$ after transfection. Luciferase assays were performed using a luciferase assay kit (E1910, Promega) according to the manufacturer's protocol. TK renilla luciferase was used for normalization in Dual Luciferase assays.

\section{FACS assays}

FACS assays were used for detection of Fas protein level similar to our published methods [24, 26, 27]. Generally, prior to fluorescent antibody staining, all cells were incubated with CD16/CD32 antibody at a concentration of $1 \mu \mathrm{g} / 10^{6} \mathrm{cells} / 100 \mu \mathrm{l}$ for 15 minutes at $4^{\circ} \mathrm{C}$ to block Fc receptors. Fluorescent antibodies and respective isotype controls were then added at a concentration of $1 \mu \mathrm{g} / 10^{6} \mathrm{cells} / 100 \mu \mathrm{l}$, and cells incubated for a further 30 minutes at $4^{\circ} \mathrm{C}$. The cells were washed once with ice-cold PBS (pH 7.2) containing $0.1 \%$ NaN3 and $0.5 \%$ BSA, and re-suspended in $300 \mu$ PBS. Cells were then labeled with PE labeled anti-mouse Fas/CD95 (eBioscience,12-0951) in PBS for $30 \mathrm{~min}$, and then washed, analyzed by FACS according to the manufacturer's instructions as described previously [35]. Flow Cytometry was performed using a FACS Calibur and data analyzed using Cell-Quest software (both from Becton Dickinson, Mountain View, CA) as described previously [26, 35-37].

\section{Statistical analysis}

Comparisons between experimental groups and relevant controls were performed by Student's t-test. $\mathrm{P}<0.05$ was considered a statistically significant difference. The inverse correlation assay was examined by Spearman correlation analysis. 


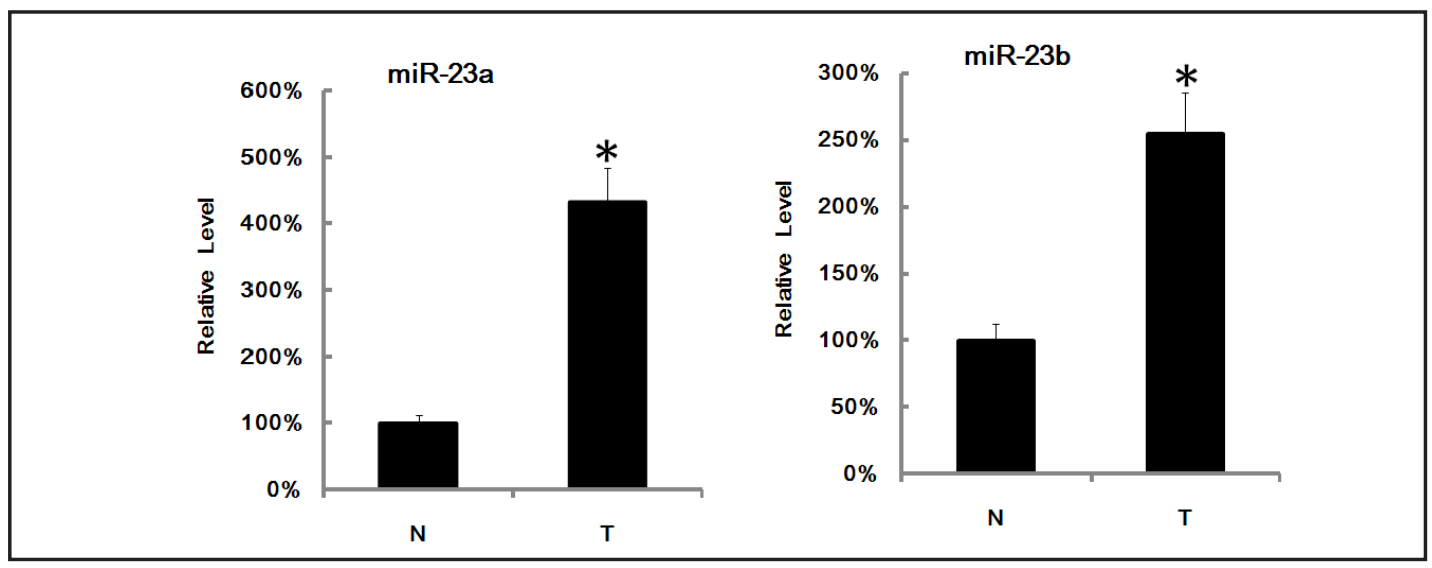

Fig. 1. MiR-23a/b was up-regulated in radiation induced lymphoma tissues. The relative expression of miR-23a/b in 9 pairs of radiation induced lymphoma tissue samples (T) and normal control thymus tissue samples $(\mathrm{N})$ were detected using real-time PCR. The relative expression level of miR-23a/b in each normal control thymus tissue samples were normalized as $1(100 \%)$ in each pair. Data are shown as the means \pm standard deviation of triplicate experiments. *: $\mathrm{P}<0.05$.

\section{Results}

MiR-23a/b is up-regulated in radiation induced thymic lymphoma tissues

To test the expression of miR-23 in radiation induced thymic lymphoma tissue samples (shorted as T, tumor) and normal control non-irradiated thymus tissue samples (shorted as N, Non-Irradiated normal control), qRT-PCR analysis of miR-23a/b expression level was performed in 9 pairs of radiation induced carcinogenesis tissue samples with normal control non-irradiated thymus tissues. It was shown that miR-23a and miR-23b expression level were significantly higher in radiation induced thymic lymphoma tissues than in matched normal control non-irradiated thymus tissues (Fig. 1).

Suppression of apoptosis by over-expression of miR-23a/b in lymphoma cells

To determine the role of miR-23a/b in cell proliferation, a miR-23a/b mimics was transfected into the murine thymic lymphoma cell line EL4 cells. The validity of miR-23a/b ectopic expression was confirmed by qRT-PCR (Fig. 2A). Also, miR-23a/b specific antisense oligo (miR-23a/b ASO) could down-regulate the expression of miR-23a/b (Fig. 2B). The total cell number of EL4 cells transfected with miR-23a/b mimics was significantly higher than the control group (Fig. 2C). Furthermore, cell apoptosis was significantly decreased after transfected with miR-23a/b mimics (Fig. 2D). These results indicated that the enhanced expression of miR-23a/b by transfection showed a pro-proliferative and oncogenic effect. Furthermore, miR-23a/b specific antisense oligo could up-regulate the apoptosis rate of EL4 cells (Fig. 2D). These results indicated a potential therapeutic target of miR-23a/b in radiation induced thymic lymphoma.

Fas is a direct target of $m i R-23 a / b$

The 3'-UTR of Fas was screened for complementarity to seed sequences of known miRNAs via bioinformatics analysis. As shown in Fig. 3A, wild type of mouse mRNA 3'UTR carried a putative miR-23a/b binding site while the 258-264 mutated mouse Fas 3' UTR failed to bind miR-23a/b. miR-23a/b significantly reduced the luciferase activity of the wild type Fas 3'UTR with respect to the negative control. However, miR-23a/b had no effect on the luciferase activity of the 258-264 mutated Fas 3'UTR (Fig. 3B). These data indicated that miR-23a/b may target Fas in a 3'UTR dependent manner. FACS assays showed that overexpression of miR-23a/b decreased the amount of Fas protein (Fig. 3C), suggesting that 


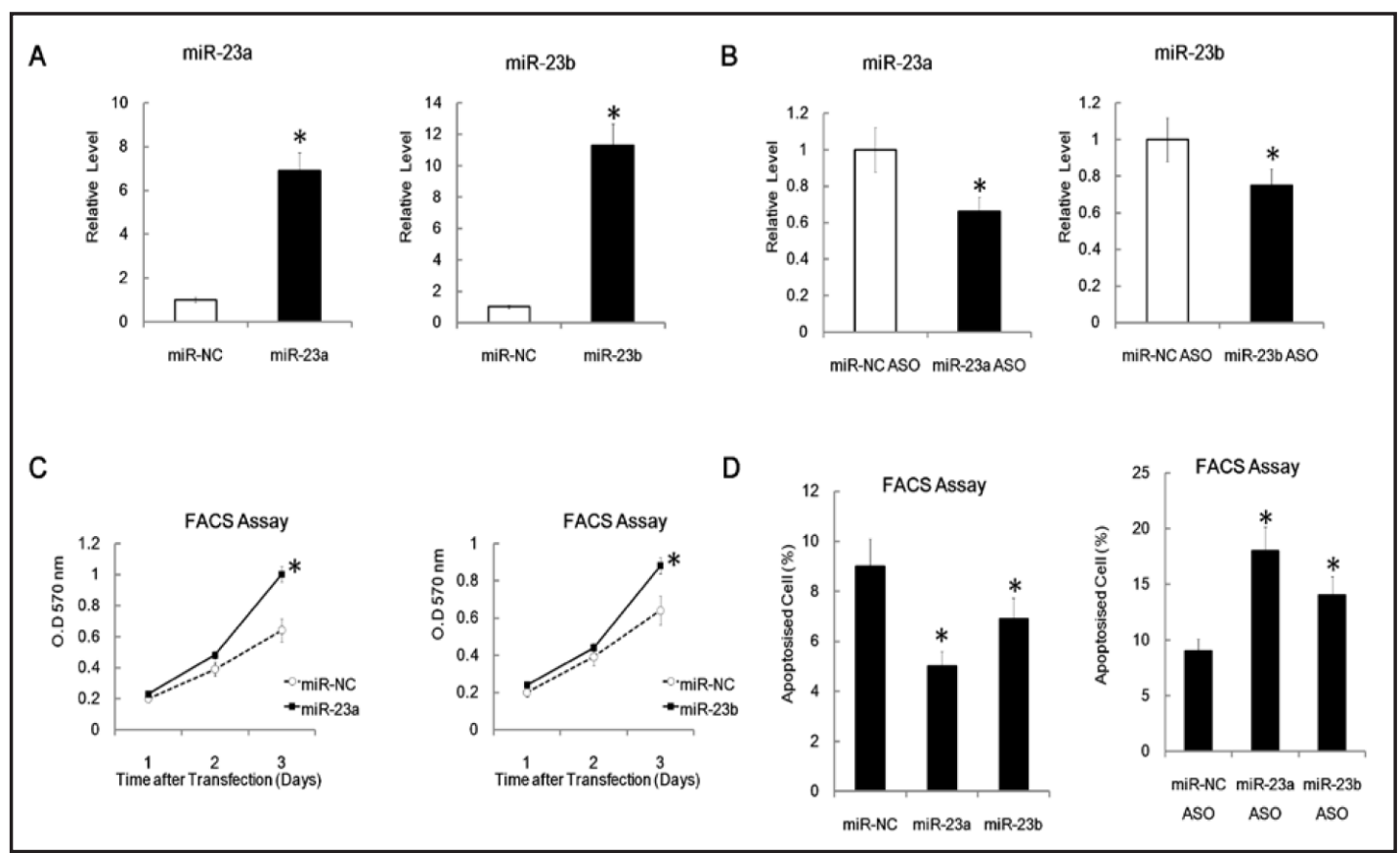

Fig. 2. The effects of ectopically expressed miR-23a/b on cell function. (A) Validation of miR-23a/b over-expression mimics (miR-23a/b). miR-23a/b mimics and nonspecific control miRNA mimics (miR-NC) were transfected into cells EL4 cells by Amaxa electroporation apparatus (Amaxa Biosystems, Koln, Germany) using Amaxa Cell Line Nucleofector Kit L as described in the material and method parts, then 24 hours later the relative levels of miR-23a/b were analyzed by q-RT-PCR. (B) Validation of miR-23a/b specific inhibitor antisense oligo (miR-23a/b ASO). (C) Different time after transfection of the miR-23a/b mimics or negative control miRNA mimics (miRN-NC), different group of EL4 cells were subjected to MTT assay. (D) MiR$23 \mathrm{a} / \mathrm{b}$ protected cells from apoptosis while miR-23a/b specific inhibitor antisense oligo (miR-23a/b ASO) enhanced apoptosis as analyzed using flow cytometry. All the experiments were performed three times and a representative one was shown. $*$ : $\mathrm{P}<0.05$.

miR-23a/b negatively regulated endogenous Fas protein expression through translational repression mechanism. Interestingly, miR-23a could repress Fas protein and the luciferase activity of the wild type Fas 3'UTR more potent than miR-23b (Fig. 3B and 3C).

The additional binding site besides conserved seed region enhanced the regulating capacity of miR-23a

Since miR-23a could repress Fas protein and the luciferase activity of the wild type Fas 3'UTR more potent than miR-23b (Fig. 3B and 3C). To investigate the mechanism, mutated Fas 3'UTR was constructed and DLR assays were performed (Fig. 4A). Consistent with Fig. 4B, miR-23a could repress Fas protein and the luciferase activity of the wild type Fas 3'UTR more potent than miR-23b and both miR-23a/b has no effect on the luciferase activity of the 258-264 mutated Fas 3'UTR. However, 246 mutated Fas 3'UTR attenuated the higher regulating capacity of miR-23a (Fig. 4B). Thus, our data also indicates that the additional binding site besides conserved seed region enhanced the regulating capacity of miR-23a.

Fas is a mediator of miR-23a/b functions and play a role in cell proliferation and apoptosis.

To explore the relevance of Fas in miR-23a/b related functions, we performed rescue experiments of Fas over-expression in cells ectopically expressing miR-23a/b. As shown in Fig. 5A, over-expression of Fas attenuated the pro-proliferation effect of miR-23a/b significantly. Furthermore, over-expression of Fas enhanced the apoptosis rate in cells with or without miR-23a/b over-expression (Fig. 5B). These data indicated that although other 
Fig. 3. $m i R-23 a / b$ targets Fas in a 3'UTR dependent manner. miR-23a/b targets Fas in a 3'UTR dependent manner. (A) The predicted miR-23a/b binding site on murine Fas mRNA 3'UTR and the mutation strategy (in red) is shown. (B) A dual luciferase assay of NIH3T3 cells co-transfected with the firefly luciferase constructs containing the wild type or 258264 mutated Fas 3'UTR and miR-23a/b mimics or scrambled negative control (miR-NC). (C) miR23a/b mimics inhibit endogenous Fas expression in EL4 cells as detected by FACS assay. All the experiments were performed three times and a representative one was shown. *: $\mathrm{P}<$ 0.05. (D) $\mathrm{miR}-23 \mathrm{a} / \mathrm{b}$ mimics inhibit endogenous Fas expression in EL4 cells as detected by qRT-PCR. All the experiments were performed three times and a representative one was shown. $*$ : $\mathrm{P}<0.05$.

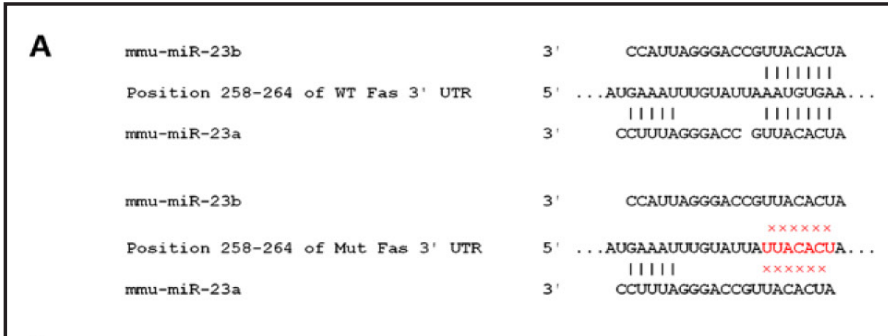

B
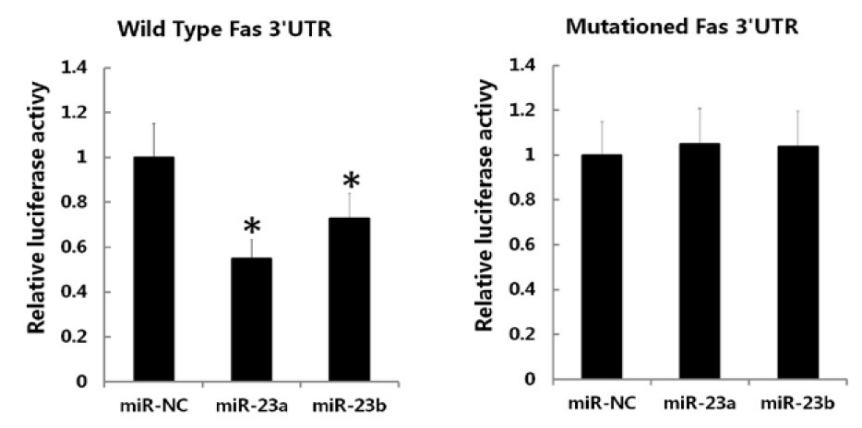

C miR-NC

miR-23a

$\operatorname{miR}-23 b$
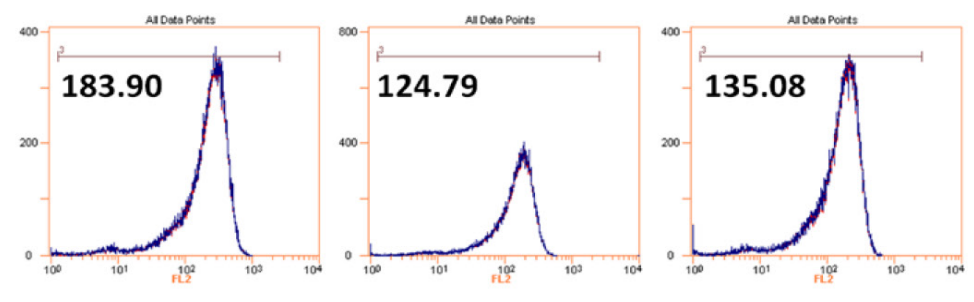

Fas-PE FL2

D
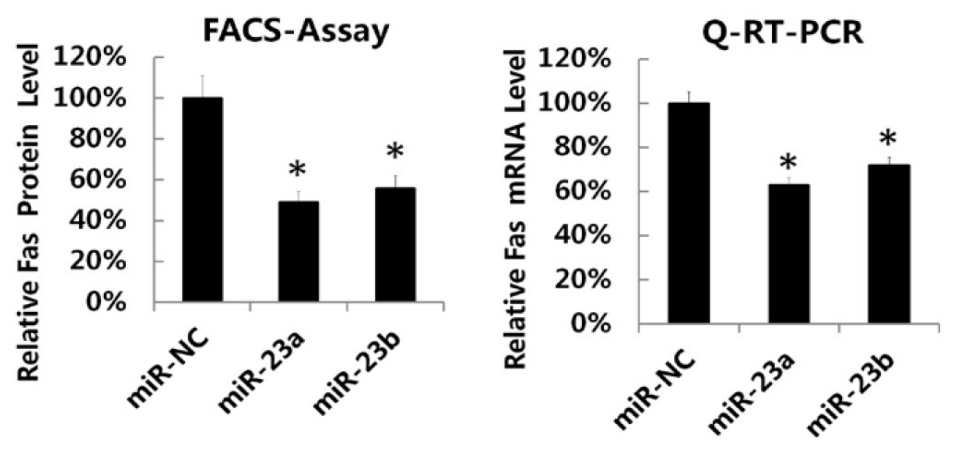

possible mediators existed, one possible downstream target of miR-23a/b was Fas, which played a role in cell proliferation and radiation-induced apoptosis.

Fas level was down-regulated in split radiation induced lymphoma tissue samples.

It was shown that Fas expression level was generally and significantly lower in radiation induced thymic lymphoma tissue samples than in matched normal control non-irradiated thymus tissue samples (Fig. 6A). Furthermore, we also found inverse correlations between Fas protein and miR-23a/b expression level among 9 pairs of different tissues (Fig. 6B). We 
Fig. 4. The additional region besides conserved seed pairing enables miR23a's higher regulation. (A) The predicted miR-23a/b binding site on murine Fas mRNA 3'UTR and the mutation strategies are shown. (B) A dual luciferase assay of NIH3T3 cells co-transfected with the firefly luciferase constructs containing the wild type or different mutated Fas 3'-UTR and miR-23a/b mimics or scrambled miRNA negative control (miR-NC). *: P < 0.05; NS: No Significant difference detected.

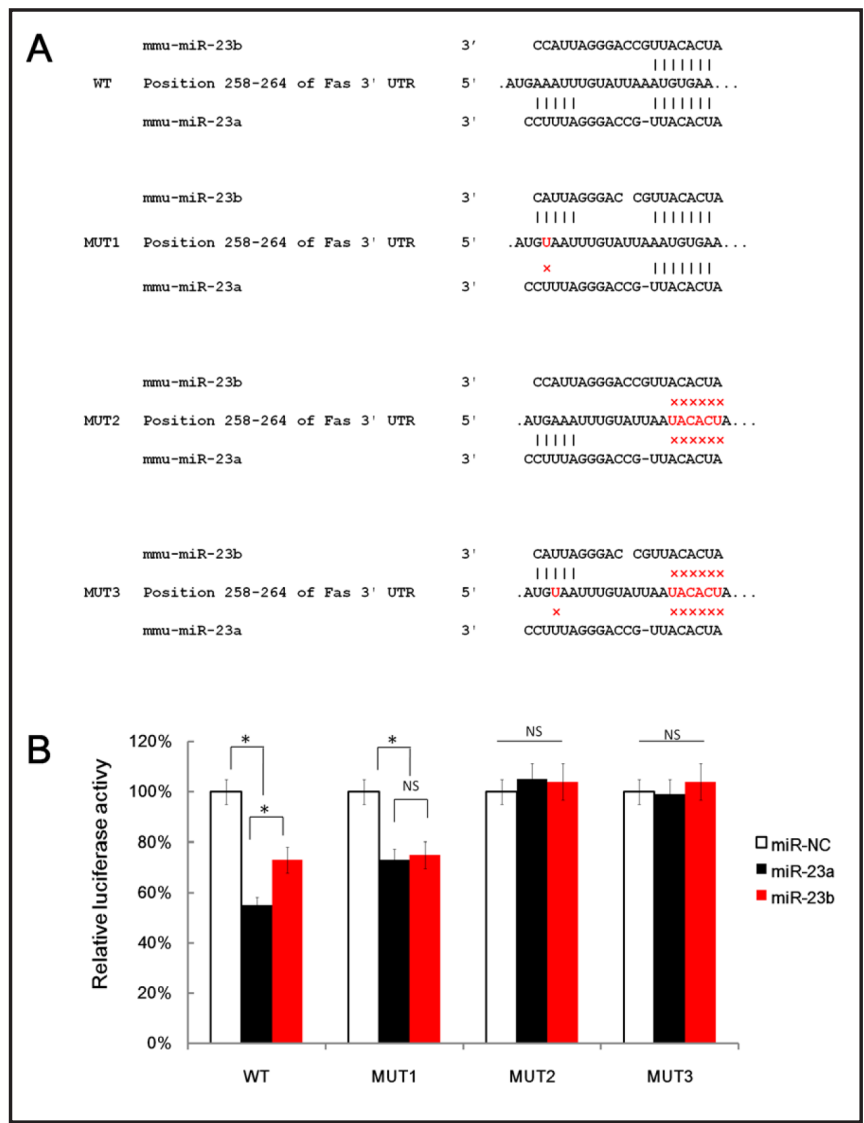

A

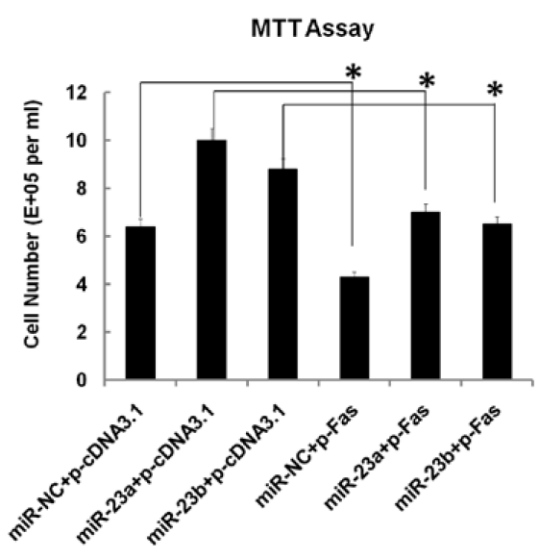

B

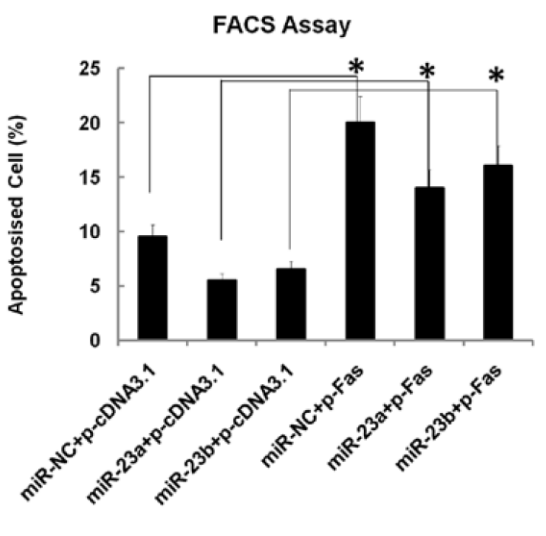

Fig. 5. Rescue effects of Fas over-expression in cells ectopically expressing of miR-23a/b.(A). Overexpression of Fas attenuated the pro-proliferation effect of miR-23a/b; Relative cell Number counting by MTT Assay. The amount of MTT formazan product, which reflects the number of cells adhering to FN, was determined by measuring absorbance with a microplate reader (B).Over-expression of Fas enhanced the apoptosis rate in cells with miR-23a/b over-expression. Ann-V/PI double staining assay and detected by FACS Assay; Null vector transfection as the control.

found that inverse correlations between Fas protein and miR-23a expression were stronger than Fas and miR-23b. However, we didn't find any inverse correlations between miR-23a and miR-23b in different radiation induced thymic lymphoma samples (Fig. 6B). 


\section{A}

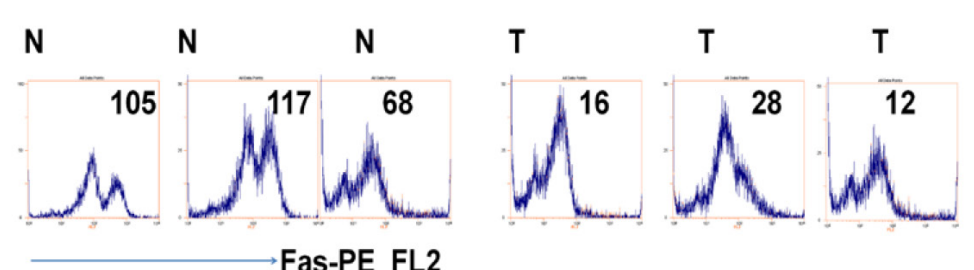

B
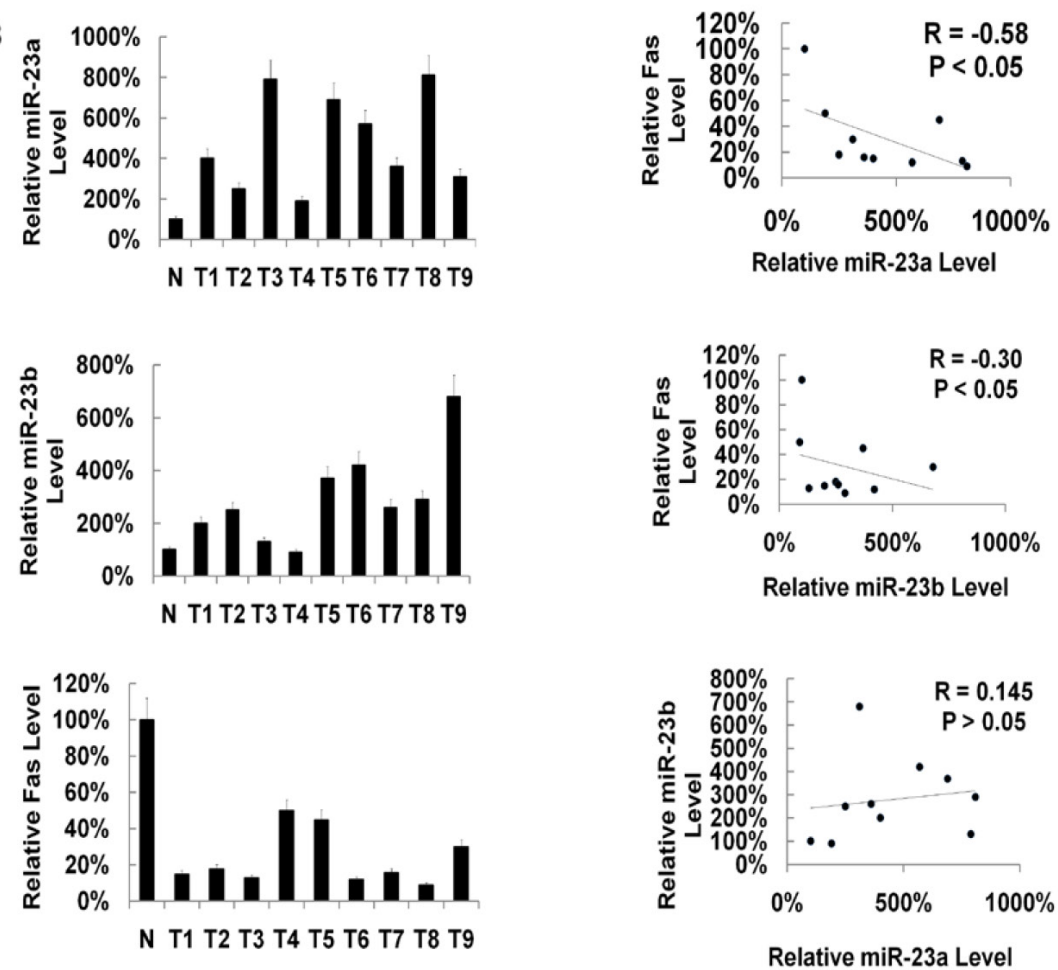

Fig. 6. Fas expression Level was down-regulated and inversely correlated with miR-23 in split radiation induced lymphoma tissue samples. (A) Fas expression level was down-regulated in split radiation induced lymphoma tissue samples: FACS assay. T: radiation induced Thymic lymphoma tissue samples (T) and N: normal control thymus tissue samples. (B) Fas protein and miR-23 expression levels are inversely correlated in radiation induced thymic lymphoma tissue samples. Real-time PCR analyses of the relative expression levels of miR-23a/b and FACS analysis of the relative expression levels of Fas protein in 9 pairs of radiation induced thymic lymphoma tissues and normal control non irradiated thymus tissue samples. (The same tissue sample was subjected to both Real-time PCR analyses and FACS analysis). The inverse correlation of Fas protein and miR-23a/b expression levels was examined by Spearman correlation analysis.

\section{Discussion}

In the last few years, several studies had shown the dys-regulation (down-regulation or up-regulation) of miRNAs in various types of cancers [5, 10-16, 24, 38, 39]. Identification of cancer-specific or cancer-related miR-s and their targets is critical for understanding their role in tumorigenesis and may be important for defining novel therapeutic targets and drugs $[2,10,40-42]$. Studies have shown that ionizing radiation is a well-known carcinogen for various human and mice tissues and it is able to initiate and promote neoplastic progression $[24,25,27,43]$. 
It is now widely recognized that the small endogenous RNAs are able to interact with many physiological essential genes. These RNAs are known to play important roles in diverse biological processes, including development, cell proliferation, apoptosis, and differentiation, and cancer development. Our paper described the gene silencing of Fas, which is a key receptor for T-cell homeostasis, by miR-23a and miR-23b during radiation carcinogenesis in mouse thymic lymphomas. To the best of our knowledge, this may be the first report describing changed expression level of miR-23a/b in radiation induced thymic lymphoma tissues in BALB/c mice. In this work, we investigated the several miRNAs of thymic lymphomas induced in BALB/c mice, we found that the level of expression of some miRNA are correspondent with result of Bueno et al [44, 45]. Like miR-21 and miR-17 were up-regulated in both models and miR-203 is down-regulated in both models (more greater in there model). However, still some miRNAs present different level of expression, such as miR-23 was only selected by our model; MiR-155 and miR10b are reverse expression in difference mouse strain [44].

MiR-23 was reported to be up-regulated in the mouse liver tumors as well as in primary human HCC [46]. MiR-23 enhances angiogenesis by promoting angiogenic signaling through targeting Sprouty2 and Sema6A proteins, which exert antiangiogenic activity. In that manner manipulating miR-23 levels may have important therapeutic implications in neovascular related disease like cancer [47]. MiR-23a promotes the growth of gastric adenocarcinoma cell line MGC803 and downregulates interleukin-6 receptor [48]. There is also a Nature retraction paper: Hes1 is a target of microRNA-23 during retinoic-acid-induced neuronal differentiation of NT2 cells [49]. Similarly, another paper reported that the protection of RPE cells against oxidative damage is afforded by miR-23a through regulation of Fas [50].

The Fas death receptor is a cell surface molecule involved in apoptosis as well as in proliferative or activating signals of many cells types. Alteration in the Fas/Fas-ligand system has been implicated in the pathogenesis of many tumor types as well as in some diseases of the immune system [51]. It has been demonstrated that mouse thymic lymphomas induced by $\gamma$-irradiation expressed lower levels of Fas mRNA, suggesting that a silencing of this gene may contribute to the development of such tumours [52]. We also found that Fas expression level was generally and significantly lower in radiation induced thymic lymphoma tissue samples than in matched normal control non-irradiated thymus tissue samples. Furthermore, we also found inverse correlations between Fas protein and miR-23a/b expression level among 9 pairs of different tissues

An interesting result is that we find that the expression pattern and function of miR23a and miR-23b are very similar to each other, however, miR-23a could repress Fas protein and the luciferase activity of the wild type Fas 3'UTR more potent than miR-23b. Our data also indicates that the additional region besides conserved seed pairing may enable miR23a's higher regulation. This is very important since traditional role of miR-mRNA binding were mostly through the conserved seed pairing region. Our data also showed that the other binding site may also play a role in miR regulation.

\section{Conclusions}

In conclusion, we found that the expression of miR-23a/b was up-regulated in radiation-induced thymic lymphoma tissue. We further identified that one direct target of miR-23a/b was pro-apoptosis molecular Fas in thymic lymphoma cells.

\section{Conflict of Interest}

The authors declare no conflict of interest. 
Li et al.: MiR-23 in Radiocarcinogenesis

\section{Acknowledgements}

This work was supported in part by the grants from National Natural Science Foundation of China (No. 31070761 and No. 31100605).

\section{References}

1 Liu C, Gao F, Li B, Mitchel RE, Liu X, Lin J, Zhao L, Cai J: Tlr4 knockout protects mice from radiation-induced thymic lymphoma by downregulation of il6 and mir-21. Leukemia 2011;25:1516-1519.

Bartel DP: Micrornas: Target recognition and regulatory functions. Cell 2009;136:215-233.

Lanford RE, Hildebrandt-Eriksen ES, Petri A, Persson R, Lindow M, Munk ME, Kauppinen S, Orum H:

Therapeutic silencing of microrna-122 in primates with chronic hepatitis c virus infection. Science 2010;327:198-201.

4 Ambros V: The functions of animal micrornas. Nature 2004;431:350-355.

5 Melton C, Judson RL, Blelloch R: Opposing microrna families regulate self-renewal in mouse embryonic stem cells. Nature 2010;463:621-626.

6 Liu C, Zhang C, Lu H, Cai J, Wang Z, Chen J, Liu F, Wu Z, Liu X, Sun W: Poly(i:C) induce bone marrow precursor cells into myeloid-derived suppressor cells. Mol Cell Biochem 2011;358:317-323.

7 Calin GA, Croce CM: Microrna signatures in human cancers. Nat Rev Cancer 2006;6:857-866.

8 Calin GA, Ferracin M, Cimmino A, Di Leva G, Shimizu M, Wojcik SE, Iorio MV, Visone R, Sever NI, Fabbri M, Iuliano R, Palumbo T, Pichiorri F, Roldo C, Garzon R, Sevignani C, Rassenti L, Alder H, Volinia S, Liu CG, Kipps TJ, Negrini M, Croce CM: A microrna signature associated with prognosis and progression in chronic lymphocytic leukemia. New Engl J Med 2005;353:1793-1801.

-9 Mayr C, Hemann MT, Bartel DP: Disrupting the pairing between let-7 and hmga2 enhances oncogenic transformation. Science 2007;315:1576-1579.

10 Mi S, Lu J, Sun M, Li Z, Zhang H, Neilly MB, Wang Y, Qian Z, Jin J, Zhang Y, Bohlander SK, Le Beau MM, Larson RA, Golub TR, Rowley JD, Chen J: Microrna expression signatures accurately discriminate acute lymphoblastic leukemia from acute myeloid leukemia. Proc Natl Acad Sci USA 2007;104:19971-19976.

11 Gottardo F, Liu CG, Ferracin M, Calin GA, Fassan M, Bassi P, Sevignani C, Byrne D, Negrini M, Pagano F, Gomella LG, Croce CM, Baffa R: Micro-rna profiling in kidney and bladder cancers. Urol Oncol 2007;25:387392.

12 Volinia S, Calin GA, Liu CG, Ambs S, Cimmino A, Petrocca F, Visone R, Iorio M, Roldo C, Ferracin M, Prueitt RL, Yanaihara N, Lanza G, Scarpa A, Vecchione A, Negrini M, Harris CC, Croce CM: A microrna expression signature of human solid tumors defines cancer gene targets. Proc Natl Acad Sci USA 2006;103:2257-2261.

13 Ciafre SA, Galardi S, Mangiola A, Ferracin M, Liu CG, Sabatino G, Negrini M, Maira G, Croce CM, Farace MG: Extensive modulation of a set of micrornas in primary glioblastoma. Biochem Bioph Res Co 2005;334:1351-1358.

14 Bloomston M, Frankel WL, Petrocca F, Volinia S, Alder H, Hagan JP, Liu CG, Bhatt D, Taccioli C, Croce CM: Microrna expression patterns to differentiate pancreatic adenocarcinoma from normal pancreas and chronic pancreatitis. JAMA 2007;297:1901-1908.

15 Marsh EE, Lin Z, Yin P, Milad M, Chakravarti D, Bulun SE: Differential expression of microrna species in human uterine leiomyoma versus normal myometrium. Fertil Steri 2008;89:1771-1776.

16 Huang S, He X, Ding J, Liang L, Zhao Y, Zhang Z, Yao X, Pan Z, Zhang P, Li J, Wan D, Gu J: Upregulation of mir-23a approximately 27 a approximately 24 decreases transforming growth factor-beta-induced tumorsuppressive activities in human hepatocellular carcinoma cells. Int J Cancer 2008;123:972-978.

17 Porkka KP, Pfeiffer MJ, Waltering KK, Vessella RL, Tammela TL, Visakorpi T: Microrna expression profiling in prostate cancer. Cancer Res 2007;67:6130-6135.

18 Barcellos-Hoff MH, Park C, Wright EG: Radiation and the microenvironment - tumorigenesis and therapy. Nat Rev Cancer 2005;5:867-875.

19 Thoms J, Goda JS, Zlotta AR, Fleshner NE, van der Kwast TH, Supiot S, Warde P, Bristow RG: Neoadjuvant radiotherapy for locally advanced and high-risk prostate cancer. Nat Rev Clin Oncol 2011;8:107-113.

20 Bewley DK: Pions and heavy ions in radiotherapy. Nature 1972;237:17-19 passim. 
21 Dange P, Sarma H, Pandey BN, Mishra KP: Radiation-induced incidence of thymic lymphoma in mice and its prevention by antioxidants. J Environ Pathol Toxicol Oncol 2007;26:273-279.

22 Villa-Morales M, Santos J, Fernandez-Piqueras J: Functional fas (cd95/apo-1) promoter polymorphisms in inbred mouse strains exhibiting different susceptibility to gamma-radiation-induced thymic lymphoma. Oncogene 2006;25:2022-2029.

23 Fu Z, Huang D, Cai J, Chen Q, Han L, Li B, Wang F, Gao J: Expression changes of erk1/2, stat3 and shp-2 in bone marrow cells from gamma-ray induced leukemia mice. J Radiat Res 2006;47:121-130.

24 Liu C, Li B, Cheng Y, Lin J, Hao J, Zhang S, Mitchel RE, Sun D, Ni J, Zhao L, Gao F, Cai J: Mir-21 plays an important role in radiation induced carcinogenesis in balb/c mice by directly targeting the tumor suppressor gene big-h3. Int J Biol Sci 2011;7:347-363.

25 Liu C, Zhang C, Mitchel RE, Cui J, Lin J, Yang Y, Liu X, Cai J: A critical role of toll-like receptor 4 (tlr4) and its' in vivo ligands in basal radio-resistance. Cell Death Dis 2013;4:e649.

-26 Liu C, Lin J, Zhao L, Yang Y, Gao F, Li B, Cui J, Cai J: Gamma-ray irradiation impairs dendritic cell migration to ccl19 by down-regulation of ccr7 and induction of cell apoptosis. Int J Biol Sci 2011;7:168-179.

27 Liu C, Zhou C, Gao F, Cai S, Zhang C, Zhao L, Zhao F, Cao F, Lin J, Yang Y, Ni J, Jia J, Wu W, Zhou L, Cui J, Zhang W, Li B, Cai J: Mir-34a in age and tissue related radio-sensitivity and serum mir-34a as a novel indicator of radiation injury. Int J Biol Sci 2011;7:221-233.

28 Hao J, Zhang S, Zhou Y, Hu X, Shao C: Microrna 483-3p suppresses the expression of dpc4/smad4 in pancreatic cancer. FEBS Lett 2011;585:207-213.

29 Hao J, Zhang S, Zhou Y, Liu C, Hu X, Shao C: Microrna 421 suppresses dpc4/smad4 in pancreatic cancer. Biochem Biophys Res Commun 2011;406:552-557.

-30 Zhang S, Hao J, Xie F, Hu X, Liu C, Tong J, Zhou J, Wu J, Shao C: Downregulation of mir-132 by promoter methylation contributes to pancreatic cancer development. Carcinogenesis 2011;32:1183-1189.

-31 Zhang Y, Wang YG, Zhang Q Liu XJ, Liu X, Jiao L, Zhu W, Zhang ZH, Zhao XL, He C: Interaction of mint2 with trka is involved in regulation of nerve growth factor-induced neurite outgrowth. J Biol Chem 2009;284:12469-12479.

-32 Su S, Li Y, Luo Y, Sheng Y, Su Y, Padia RN, Pan ZK, Dong Z, Huang S: Proteinase-activated receptor 2 expression in breast cancer and its role in breast cancer cell migration. Oncogene 2009;28:3047-3057.

-33 Rui Y, Liu X, Li N, Jiang Y, Chen G, Cao X, Wang J: Pecam-1 ligation negatively regulates tlr4 signaling in macrophages. J Immunol 2007;179:7344-7351.

34 Zhang Y, Zhang JW, Lv GY, Xie SL, Wang GY: Effects of stat3 gene silencing and rapamycin on apoptosis in hepatocarcinoma cells. Int J Med Sci 2012;9:216-224.

-35 Chen T, Guo J, Yang M, Han C, Zhang M, Chen W, Liu Q, Wang J, Cao X: Cyclosporin a impairs dendritic cell migration by regulating chemokine receptor expression and inhibiting cyclooxygenase-2 expression. Blood 2004;103:413-421.

-36 Ohl L, Mohaupt M, Czeloth N, Hintzen G, Kiafard Z, Zwirner J, Blankenstein T, Henning G, Forster R: Ccr7 governs skin dendritic cell migration under inflammatory and steady-state conditions. Immunity 2004;21:279-288.

37 Zhang M, Tang H, Guo Z, An H, Zhu X, Song W, Guo J, Huang X, Chen T, Wang J, Cao X: Splenic stroma drives mature dendritic cells to differentiate into regulatory dendritic cells. Nat Immunol 2004;5:1124-1133.

38 He L, He X, Lowe SW, Hannon GJ: Micrornas join the p53 network--another piece in the tumoursuppression puzzle. Nat Rev Cancer 2007;7:819-822.

39 Nicoloso MS, Spizzo R, Shimizu M, Rossi S, Calin GA: Micrornas--the micro steering wheel of tumour metastases. Nat Rev Cancer 2009;9:293-302.

40 Hammond SM, Sharpless NE: Hmga2, micrornas, and stem cell aging. Cell 2008;135:1013-1016.

41 Bartel DP: Micrornas: Genomics, biogenesis, mechanism, and function. Cell 2004;116:281-297.

42 Chen CZ, Li L, Lodish HF, Bartel DP: Micrornas modulate hematopoietic lineage differentiation. Science 2004;303:83-86.

43 Little JB: Radiation carcinogenesis. Carcinogenesis 2000;21:397-404.

44 Bueno MJ, Gomez de Cedron M, Gomez-Lopez G, Perez de Castro I, Di Lisio L, Montes-Moreno S, Martinez N, Guerrero M, Sanchez-Martinez R, Santos J, Pisano DG, Piris MA, Fernandez-Piqueras J, Malumbres M: Combinatorial effects of micrornas to suppress the myc oncogenic pathway. Blood 2011;117:6255-6266. 
Li et al.: MiR-23 in Radiocarcinogenesis

45 Bueno MJ, Perez de Castro I, Gomez de Cedron M, Santos J, Calin GA, Cigudosa JC, Croce CM, FernandezPiqueras J, Malumbres M: Genetic and epigenetic silencing of microrna-203 enhances abl1 and bcr-abl1 oncogene expression. Cancer Cell 2008;13:496-506.

46 Wang B, Hsu SH, Frankel W, Ghoshal K, Jacob ST: Stat3-mediated activation of microrna-23a suppresses gluconeogenesis in hepatocellular carcinoma by down-regulating glucose-6-phosphatase and peroxisome proliferator-activated receptor gamma, coactivator 1 alpha. Hepatology 2012;56:186-197.

-47 Zhou Q Gallagher R, Ufret-Vincenty R, Li X, Olson EN, Wang S: Regulation of angiogenesis and choroidal neovascularization by members of microrna-23 27 24 clusters. Proc Natl Acad Sci USA 2011;108:82878292.

48 Zhu LH, Liu T, Tang H, Tian RQ, Su C, Liu M, Li X: Microrna-23a promotes the growth of gastric adenocarcinoma cell line mgc803 and downregulates interleukin-6 receptor. FEBS J 2010;277:3726-3734.

49 Kawasaki H, Taira K: Hes1 is a target of microrna-23 during retinoic-acid-induced neuronal differentiation of nt2 cells. Nature 2003;423:838-842.

50 Lin H, Qian J, Castillo AC, Long B, Keyes KT, Chen G, Ye Y: Effect of mir-23 on oxidant-induced injury in human retinal pigment epithelial cells. Invest Ophthalmol Vis Sci 2011;52:6308-6314.

51 Krammer PH: Cd95's deadly mission in the immune system. Nature 2000;407:789-795.

52 Santos J, Herranz M, Fernandez M, Vaquero C, Lopez P, Fernandez-Piqueras J: Evidence of a possible epigenetic inactivation mechanism operating on a region of mouse chromosome 19 in gamma-radiationinduced thymic lymphomas. Oncogene 2001;20:2186-2189. 